\title{
Adjuvant FOLFOX-4 in patients with radically resected gastric cancer: Tolerability and prognostic factors
}

\author{
CHIARA CARLOMAGNO ${ }^{1 *}$, ELIDE MATANO ${ }^{1 *}$, ROBERTO BIANCO $^{1}$, CAROLINA CIMMINIELLO $^{1}$, \\ ANTONELLA PRUDENTE ${ }^{1}$, CLORINDO PAGLIARULO ${ }^{1}$, ANNA CRISPO $^{3}$, LUCIA CANNELLA ${ }^{1}$, \\ ALFONSO DE STEFANO $^{1}$, FRANCESCO PAOLO D'ARMIENTO ${ }^{2}$ and SABINO DE PLACIDO ${ }^{1}$

\begin{abstract}
Dipartimenti di ${ }^{1}$ Endocrinologia ed Oncologia Molecolare e Clinica, e ${ }^{2}$ Scienze Biomorfologiche e Funzionali, Università Federico II; ${ }^{3}$ Struttura Semplice Dipartimentale di Epidemiologia, Istituto Nazionale Tumori,

Fondazione Pascale, Naples, Italy
\end{abstract}

Received February 24, 2010; Accepted April 26, 2010

DOI: 10.3892/etm_00000096

\begin{abstract}
The aim of the present study was to evaluate the toxicity and efficacy of the FOLFOX-4 regimen as adjuvant chemotherapy in patients with gastric cancer after radical surgery. Fifty-four patients (1 stage Ib, 6 stage II, 22 stage IIIa, 14 stage IIIb and 11 stage IV) received 8-12 cycles of FOLFOX-4 (oxaliplatin $85 \mathrm{mg} / \mathrm{m}^{2}$, Day 1; leucovorin $100 \mathrm{mg} /$ $\mathrm{m}^{2}$ i.v., Days 1 and 2; 5-fluorouracil $400 \mathrm{mg} / \mathrm{m}^{2}$ i.v. bolus, Days 1 and 2 and $600 \mathrm{mg} / \mathrm{m}^{2}$ in $22 \mathrm{~h}$ i.v. continuous infusion, Days 1 and 2; every 14 days). Toxicity was recorded at each cycle according to the National Cancer Institute Common Toxicity Criteria. Disease-free (DFS) and overall survival (OS) were calculated according to the Kaplan-Meier method. Thirty-eight patients (70.4\%) completed the prescribed number of cycles of chemotherapy. The toxicity was mild. Grade 3-4 neutropenia occurred in $57 \%$ of patients, thrombocytopenia and anemia in $2 \%$ of cases. Peripheral neuropathy was experienced by $46 \%$ of the patients (grade 4 in $2 \%$ of cases). Five patients experienced grade 3 gastrointestinal toxicity. After a median follow-up of 33.1 months, 17 patients relapsed and 17 succumbed to the disease. The mean observed DFS and OS were 49.7 months (range 40.7-58.8) and 57.9 months (range 49.6-66.2), respectively. At univariate analysis, females and patients who had received $<8$ cycles of chemotherapy had a significantly worse probability of DFS and OS. The Cox model showed gender to be independent of the factors affecting DFS. Adjuvant FOLFOX-4 is feasible and well-tolerated in patients radically resected for gastric cancer. Receiving $<4$ months of adjuvant FOLFOX-4 could be detrimental to prognosis.
\end{abstract}

Correspondence to: Dr Chiara Carlomagno, Dipartimento di Endocrinologia ed Oncologia Molecolare e Clinica, Università Federico II, Via Sergio Pansini 5, 80131 Naples, Italy

E-mail: chiara.carlomagno@unina.it

${ }^{*}$ Contributed equally

Key words: gastric cancer, oxaliplatin, adjuvant

\section{Introduction}

Gastric cancer is the fourth most common malignancy and the second leading cause of cancer-related death in the world (1). Incidence rates vary across continents, being higher in Asia, Central and South America and Europe (1). At least in developed counties, both incidence and death rates have been constantly decreasing in the last 50 years. Furthermore, according to the Surveillance, Epidemiology and End Results database, the 5-year survival for all gastric cancer patients treated in the US increased by 50\% from 1975 to 2003 (from 16 to $24 \%$ ). However, in 200821,500 new diagnoses of gastric cancer were estimated in the US (2) and 12,600 in Italy (http:// www.tumori.net/stime).

As expected, patients with localized disease have a higher 5 -year survival rate $(82 \%)$ compared to patients with regional (24\%) or distant metastases (3\%) (2). In Western counties, only $25-40 \%$ of the patients have localized disease at diagnosis, whereas such a subgroup is much larger in Japan and in countries that adopt aggressive screening programs.

Surgical resection of the primary tumor and regional lymph nodes is the fundamental treatment for gastric cancer. Although extensive lymphadenectomy (D2 resection) is the standard procedure in Japan since the 1980's (3), four prospective randomized trials that assessed the role of D1 (peri-gastric lymph nodes along the lesser and the greater curvature) vs. D2 (including lymph nodes along the left gastric artery, the common hepatic artery, the celicac trunk, the splenic hilum and the splenic artery) resection in the management of gastric cancer failed to demonstrate any advantage in terms of survival in favor of extended surgery (4-7).

In Western countries, more than $50 \%$ of the radically resected patients experience local or distant recurrence, thus prompting the evaluation of the best surgical procedure and the best complementary strategy to surgery. The role of chemotherapy as adjuvant treatment has been controversial for a long time. Several randomized trials run in Western countries during the '80s and '90s failed to demonstrate a clear survival benefit for post-operative chemotherapy as compared to surgery alone, mostly because they were underpowered and had a small sample size (8-21). 
A great number of meta-analyses has been performed, including published trials comparing adjuvant chemotherapy to surgery alone (22-33). Most of them have suggested a small survival advantage for adjuvant treatment, but such data were considered unconvincing due to the different selection of the considered trials, the inconsistent surgical and medical treatment and, in some cases, the questionable methodology. Moreover, evidence from large, well-designed, randomized trials is more conclusive and easier to translate into clinical practice than suggestions from meta-analyses of small, underpowered trials. Thus, in the 1990's the effort of researchers worldwide was focused on large-sized, sufficiently powered trials designed to evaluate the benefit of adjuvant therapy over surgery alone.

In recent years, three pivotal studies carried out in the US, Europe and Japan, respectively, demonstrated the efficacy on survival of three different strategies of adjuvant treatment. The INT-0116 trial showed that post-operative chemoradiotherapy with 5-fluorouracil + leucovorin (5FU-LV) prolonged the survival of patients radically resected for adenocarcinoma of the stomach or gastroesophageal junction (34). The MAGIC trial demonstrated an improvement in disease-free survival (DFS) and overall survival (OS) when 3 cycles of ECF (epirubicin, cisplatin, 5FU) were administered before and after surgery in patients with gastric or lower esophageal cancer (35). The ACTS-GC group in Japan found that 1 year of treatment with the oral fluoropyimidine S-1 prolonged the survival of Asian patients who had undergone a D2 dissection for stage II-III gastric cancer (36).

Cisplatin and 5FU are the most commonly used drugs for gastric cancer and are considered milestones for chemotherapy both in metastatic and in an adjuvant setting. However, the best regimen for adjuvant treatment remains under evaluation, as the best duration is undefined. Oxaliplatin was recently demonstrated to be as active as cisplatin in metastatic gastric disease (37), less toxic and more manageable. Thus, it may replace cisplatin in multi-drug regimens.

The association of 5FU-LV and oxaliplatin is a very active regimen in metastatic colorectal cancer and is the standard adjuvant chemotherapy for stage III colon cancer, since it demonstrated clear survival advantages over 5FU-LV alone $(38,39)$.

Based on this evidence, patients with stage II-III-IV gastric cancer who had undergone radical surgery were treated with adjuvant FOLFOX-4; here, we report our experience.

\section{Materials and methods}

Fifty-four patients referred to our institution between October 2002 and June 2008 were enrolled for the present study. All patients, after radical surgery for gastric cancer, received adjuvant FOLFOX-4 (oxaliplatin 85 mg/m², Day 1; LV $100 \mathrm{mg} / \mathrm{m}^{2}$ i.v., Days 1 and 2; 5FU $400 \mathrm{mg} / \mathrm{m}^{2}$ i.v. bolus, Days 1 and 2; $5 \mathrm{FU} 600 \mathrm{mg} / \mathrm{m}^{2}$ in $22 \mathrm{~h}$ i.v. continuous infusion, Days 1 and 2; every 14 days) for 8 or 12 cycles.

Patients were monitored at each cycle of chemotherapy by history, physical examination and complete biochemistry; blood count was performed once a week during chemotherapy. Toxicity was graded according to the National Cancer Institute Common Toxicity Criteria, version 3.0.
Table I. Patients and tumor characteristics.

\begin{tabular}{lcc}
\hline & $\mathrm{n}$ & Percentage \\
\hline Gender & & \\
Male & 41 & 75.9 \\
Female & 13 & 24.1 \\
Age (median/range) & 61 & $33-77$ \\
Primary tumour site & & \\
Cardia & 4 & 7.4 \\
Fundus & 3 & 5.6 \\
Body & 33 & 61.1 \\
Antrum/pylorus & 12 & 22.2 \\
Gastric stump & 2 & 3.7 \\
Gastrectomy & & \\
Total & 30 & 55.6 \\
Partial & 24 & 44.4 \\
Basal hemoglobin (n=51) & & 27.5 \\
$<11$ mg/ml & 14 & 72.5 \\
$\geq 11$ mg/ml & 37 & \\
\hline
\end{tabular}

Staging procedures performed prior to the beginning of the treatment included blood cell count, biochemistry, blood CEA level and thorax-abdomen-pelvis CT scan. Follow-up visits were scheduled every 4 months during the first year and every 6 months thereafter. Esophagogastroduodenoscopy and thorax-abdomen-pelvis CT scan were performed yearly, and hematology, biochemistry and blood CEA levels were repeated every 4 or 6 months. Bone scan, PET/CT scan or magnetic resonance were executed only when clinically required.

DFS was defined as the time elapsed between the date of surgery and the occurrence of local relapse, distant metastases or death without recurrence; OS was defined as the time elapsed between the date of surgery and the date of death. Estimation of likelihood events for relapse or death was calculated according to the Kaplan-Meier method (40). Statistical differences between curves were calculated using the log-rank test (41). Multivariate analysis was performed using the Cox proportional hazard model (42) to estimate the hazard ratio and relative $95 \%$ confidence intervals $(95 \% \mathrm{CI})$ for each covariate. A p-value of $\leq 0.05$ was considered statistically significant. Statistical analysis was performed with SPSS (version 16.0; SPSS, Inc., Chicago, IL, USA).

\section{Results}

The main patient characteristics are reported in Table I. They were mostly male, with a median age of 61 years. More than half of the patients received a total gastrectomy. The median value of pre-chemotherapy hemoglobin was $12.1 \mathrm{~g} / \mathrm{dl}$ in men and $11.7 \mathrm{~g} / \mathrm{dl}$ in women. Thirteen patients started adjuvant chemotherapy having $<11 \mathrm{~g} / \mathrm{dl}$ of hemoglobin.

The primary tumor was located mostly in the mid-lower part of the stomach; $75 \%$ were poorly differentiated. The median number of the examined lymph nodes was 19 (range $2-40) ; 92.6 \%$ of the patients had positive lymph nodes and 
Table II. Pathological characteristics of the primary tumor.

\begin{tabular}{|c|c|c|}
\hline & $\mathrm{n}$ & Percentage \\
\hline \multicolumn{3}{|l|}{$\mathrm{T}$ primary ${ }^{\mathrm{a}}$} \\
\hline 1 & 1 & 1.8 \\
\hline 2 & 5 & 9.3 \\
\hline 3 & 38 & 70.4 \\
\hline 4 & 10 & 18.5 \\
\hline \multicolumn{3}{|l|}{$\mathrm{N}$ primary ${ }^{\mathrm{a}}$} \\
\hline $\mathrm{N}^{-}$ & 4 & 7.4 \\
\hline N1 & 31 & 57.4 \\
\hline $\mathrm{N} 2$ & 14 & 25.9 \\
\hline N3 & 5 & 9.3 \\
\hline \multicolumn{3}{|l|}{ UICC-TNM stage ${ }^{a}$} \\
\hline $\mathrm{Ib}$ & 1 & 1.8 \\
\hline II & 6 & 11.1 \\
\hline IIIa & 22 & 40.7 \\
\hline IIIb & 14 & 25.9 \\
\hline $\mathrm{IV}^{\mathrm{b}}$ & 11 & 20.4 \\
\hline \multicolumn{3}{|l|}{ Examined lymph nodes } \\
\hline$\leq 15$ & 23 & 42.6 \\
\hline$>15$ & 31 & 57.4 \\
\hline \multicolumn{3}{|l|}{ Histology } \\
\hline Adenocarcinoma & 44 & 81.5 \\
\hline Signet ring cell & 5 & 9.3 \\
\hline Mucinous adenocarcinoma & 4 & 7.4 \\
\hline Other & 1 & 1.8 \\
\hline \multicolumn{3}{|l|}{ Grading } \\
\hline Well differentiated & 6 & 11.1 \\
\hline Intermediate & 7 & 13.0 \\
\hline Poorly differentiated & 41 & 75.9 \\
\hline
\end{tabular}

${ }^{\mathrm{a} U I C C-T N M}$ classification, 6th edition, 2002; ${ }^{\mathrm{T}} \mathrm{T} 4$ or N3.

$87 \%$ of the cases were stage III or IV (T4 primary or N3 nodal status). Detailed pathological tumor characteristics are listed in Table II.
The median time elapsed from surgery to the commencement of adjuvant chemotherapy was 6 weeks (range 3-14); 14 (25.9\%) patients started chemotherapy $\geq 8$ weeks from surgery.

A total of 463 cycles of chemotherapy were administered; the median number of the received cycles of FOLFOX-4 was 8 (range 1-12). Twenty-two and 16 patients completed the 8 or 12 prescribed cycles, respectively; 3 patients progressed during chemotherapy, 1 patient died 14 days after the 4 th cycle of chemotherapy, in 7 cases FOLFOX-4 was stopped due to toxicity ( 3 due to hematological, 1 for severe mucositis and 3 due to both hematological and gastrointestinal adverse events) and 5 patients refused to complete the scheduled number of cycles.

Overall chemotherapy was well tolerated, and registered adverse events were comparable to those reported with adjuvant FOLFOX-4 in colorectal cancer. Grade 3-4 hematological toxicity was observed in 57\% (neutropenia), $2 \%$ (thrombocytopenia) and 2\% (anemia) of the patients. One patient received 5 blood transfusions because of grade 4 anemia. Peripheral neuropathy was experienced by $46 \%$ of the patients, but it was grade 4 only in $2 \%$ of the cases. Grade 3 gastrointestinal toxicity occurred only in 5 cases. Table III presents in detail the worse adverse events experienced per patient.

After a median follow-up of 33.1 months (range 3.5-79.4) from surgery, 17 (31.5\%) patients relapsed (4 peritoneal carcinosis, 2 liver, 2 perianastomotic, 2 lung, 1 suprarenal gland and 6 multiple sites) and $17(31.5 \%)$ sucuumbed to the disease. The mean observed DFS and OS were 49.7 months (range 40.7-58.8) and 57.9 months (range 49.6-66.2), respectively. The estimated 3-year DFS and 3-year OS were 57 and 67\%, respectively. The causes of death were metastatic disease in 12 cases, cardiovascular event in 4 and sudden death in 1 case. The median number of days elapsed from the end of chemotherapy and the date of the 5 deaths without recurrence was 428 days (range 14-1,104); 2 patients died of myocardial infarction and ictus, respectively, within 60 days from the end of chemotherapy.

After relapse, $11(64.7 \%)$ patients received further treatment (chemotherapy or radiotherapy); 4 patients received 2 or more lines of chemotherapy for metastatic disease.

Table III. Worse experienced toxicity among the 54 treated patients.

\begin{tabular}{|c|c|c|c|c|c|c|c|c|c|c|}
\hline \multirow[t]{2}{*}{ Adverse event } & \multicolumn{2}{|c|}{ G0 } & \multicolumn{2}{|c|}{ G1 } & \multicolumn{2}{|c|}{$\mathrm{G} 2$} & \multicolumn{2}{|c|}{ G3 } & \multicolumn{2}{|c|}{ G4 } \\
\hline & $\mathrm{n}$ & $\%$ & $\mathrm{n}$ & $\%$ & $\mathrm{n}$ & $\%$ & $\mathrm{n}$ & $\%$ & $\mathrm{n}$ & $\%$ \\
\hline Nausea & 33 & 61.1 & 20 & 37.0 & 1 & 1.8 & - & - & - & - \\
\hline Vomiting & 39 & 72.2 & 9 & 16.7 & 4 & 7.4 & 2 & 3.7 & - & - \\
\hline Diarrhea & 27 & 50.0 & 20 & 37.0 & 5 & 9.3 & 2 & 3.7 & - & - \\
\hline Stomatitis & 43 & 79.6 & 6 & 11.1 & 4 & 7.4 & 1 & 1.8 & - & - \\
\hline Neutropenia & 15 & 27.8 & 5 & 9.3 & 3 & 5.6 & 21 & 38.9 & 10 & 18.5 \\
\hline Anemia & 12 & 22.2 & 28 & 51.8 & 13 & 24.1 & - & - & 1 & 1.8 \\
\hline Thrombocytopenia & 18 & 33.3 & 31 & 57.4 & 4 & 7.4 & 1 & 1.8 & - & - \\
\hline Peripheral neuropathy & 29 & 53.7 & 21 & 38.9 & 3 & 5.6 & - & - & 1 & 1.8 \\
\hline Asthenia & 38 & 70.4 & 12 & 22.2 & 3 & 5.6 & 1 & 1.8 & - & - \\
\hline
\end{tabular}


Table IV. Univariate analysis.

\begin{tabular}{|c|c|c|c|c|}
\hline Variable & Probability of DFS $(\%)^{\mathrm{a}}$ & P-value & Probability of OS $(\%)^{\mathrm{a}}$ & P-value \\
\hline Age, in years & & 0.20 & & 0.10 \\
\hline$\leq 65$ & 61.1 & & 75.0 & \\
\hline$>65$ & 50.0 & & 55.6 & \\
\hline Gender & & 0.01 & & 0.02 \\
\hline Male & 65.8 & & 78.1 & \\
\hline Female & 30.7 & & 38.5 & \\
\hline Primary tumor & & 0.80 & & 0.60 \\
\hline pT1 & 100.0 & & 100.0 & \\
\hline pT2 & 60.0 & & 60.0 & \\
\hline pT3 & 57.9 & & 71.1 & \\
\hline pT4 & 50.0 & & 60.0 & \\
\hline Nodal status & & 0.40 & & 0.09 \\
\hline pNO & 75.0 & & 100.0 & \\
\hline $\mathrm{pN} 1$ & 64.5 & & 74.2 & \\
\hline $\mathrm{pN} 2$ & 42.9 & & 57.1 & \\
\hline $\mathrm{pN} 3$ & 40.0 & & 40.0 & \\
\hline UICC-TNM stage & & 0.50 & & 0.10 \\
\hline I-II & 71.4 & & 85.7 & \\
\hline III & 58.3 & & 72.2 & \\
\hline IV & 45.4 & & 45.5 & \\
\hline No. of examined nodes & & 0.08 & & 0.20 \\
\hline$\leq 15$ & 69.6 & & 73.9 & \\
\hline$>15$ & 48.4 & & 64.5 & \\
\hline Grading & & 0.50 & & 0.90 \\
\hline G1-G2 & 69.2 & & 69.2 & \\
\hline G3 & 53.7 & & 68.2 & \\
\hline Basal hemoglobin & & 0.90 & & 0.90 \\
\hline$<11 \mathrm{mg} / \mathrm{ml}$ & 46.1 & & 61.5 & \\
\hline$\geq 11 \mathrm{mg} / \mathrm{ml}$ & 53.0 & & 71.1 & \\
\hline Interval surgery-chemotherapy & & 0.90 & & 0.90 \\
\hline$\leq 8$ weeks & 55.5 & & 65.0 & \\
\hline$>8$ weeks & 64.3 & & 78.6 & \\
\hline No. of received cycles of $\mathrm{CT}$ & & 0.05 & & 0.007 \\
\hline$\geq 8$ & 63.4 & & 78.1 & \\
\hline$<8$ & 38.5 & & 38.5 & \\
\hline
\end{tabular}

${ }^{a}$ Calculated for the entire period of observation.

Upon univariate analysis (Table IV), females and patients who received $<8$ cycles of adjuvant chemotherapy had a significantly worse probability of DFS and OS. KaplanMeier curves for DFS and OS, according to delivered cycles of FOLFOX-4, are depicted in Fig. 1A and B. The interval between surgery and the initiation of adjuvant treatment did not affect the long-term outcome.

Upon multivariate analysis, in a model including age, gender and TNM stage as adjusting covariates, females showed a 2.6-fold risk of recurrence and death $(\mathrm{p}=0.04)$. The risk of death was significantly affected by age $(\mathrm{HR}=4.1$, $\mathrm{p}=0.01$ ) and the number of delivered cycles of chemotherapy $(\mathrm{HR}=2.78, \mathrm{p}=0.04)$. However, in a model excluding the patients who died for causes other than the tumor, age lost significance (Table V). The interactions gender-stage and gender-number of delivered cycles were not significant in the Cox model.

\section{Discussion}

The optimum regimen and the optimal duration of adjuvant or neo-adjuvant chemotherapy after radical surgery of patients with gastric cancer remains in debate. The three pivotal trials demonstrated that 5 cycles of 5FU-FA + radiotherapy (34), or 1 year of oral fluoropyrimidine (36), or 6 cycles of poly-chemotherapy (ECF) (35), produce survival benefit over surgery alone. 

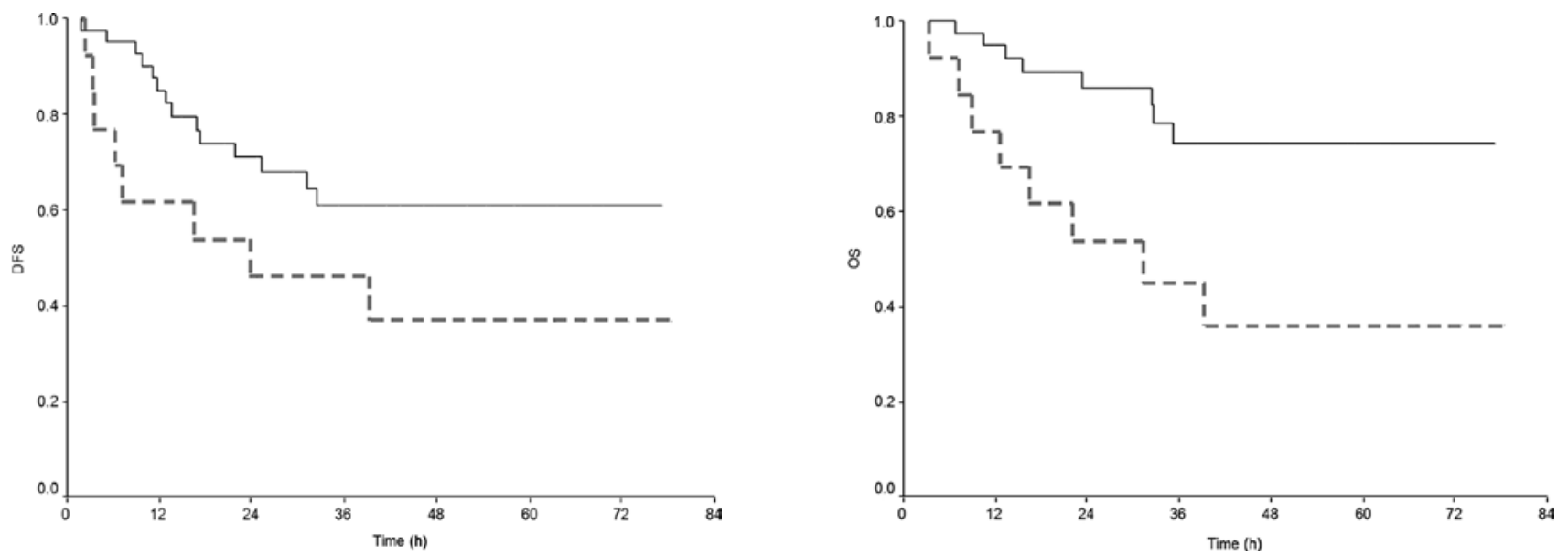

Figure 1. Disease-free (DFS) (A) and overall survival (OS) (B) according to the number of delivered cycles of adjuvant chemotherapy ( $\geq 8$ cycles, solid line; $<8$ cycles, dashed line).

Table V. Multivariate analysis.

\begin{tabular}{|c|c|c|c|c|}
\hline \multirow[t]{2}{*}{ Variable } & \multicolumn{2}{|c|}{ Disease-free survival } & \multicolumn{2}{|c|}{ Overall survival } \\
\hline & Hazard ratio $^{\mathrm{a}}$ & P-value $(95 \% \mathrm{CI})$ & Hazard ratio $^{\mathrm{a}}$ & P-value $(95 \% \mathrm{CI})$ \\
\hline Age, in years & & 0.10 & & $0.01^{\mathrm{b}}$ \\
\hline$\leq 65$ & $1^{\mathrm{c}}$ & & $1^{\mathrm{c}}$ & \\
\hline$>65$ & 2.0 & $(0.8-5.2)$ & $4.1^{\mathrm{b}}$ & $(1.3-12.6)^{\mathrm{b}}$ \\
\hline Gender & & 0.04 & & 0.04 \\
\hline Male & $1^{\mathrm{c}}$ & & $1^{\mathrm{c}}$ & \\
\hline Female & 2.6 & $(1.1-6.4)$ & $2.6^{\mathrm{b}}$ & $(1.0-7.0)$ \\
\hline UICC-TNM stage & & 0.60 & & 0.07 \\
\hline I-II & $1^{\mathrm{c}}$ & & $1^{\mathrm{c}}$ & \\
\hline III & 1.6 & $(0.3-7.3)$ & 2.3 & $(0.3-19.2)$ \\
\hline IV & 2.3 & $(0.4-13.8)$ & 8.5 & $(0.8-90.5)$ \\
\hline No. of examined nodes & & 0.10 & & 0.35 \\
\hline $\mathrm{N}^{+} \leq 15$ & $1^{\mathrm{c}}$ & & $1^{\mathrm{c}}$ & \\
\hline $\mathrm{N}^{+}>15$ & 1.9 & $(0.8-4.7)$ & 1.5 & $(0.6-4.2)$ \\
\hline No. of received cycles of CT & & 0.20 & & 0.04 \\
\hline$\geq 8$ & $1^{\mathrm{c}}$ & & $1^{\mathrm{c}}$ & \\
\hline$<8$ & 1.7 & $(0.7-4.2)$ & 2.78 & $(1.1-7.1)$ \\
\hline
\end{tabular}

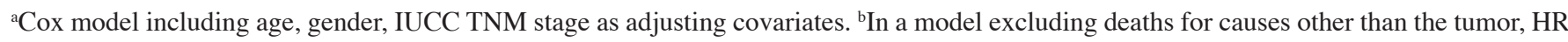
for age $=2.3(95 \% \mathrm{CI}, 0.6-8.3), \mathrm{p}=0.2{ }^{~}{ }^{~}$ Reference category. CT, chemotherapy.

Evidence suggests that the duration of adjuvant chemotherapy is considered an independent prognostic factor for DFS (43) or mortality risk (44) in colon and ovarian cancer (45). Our analysis suggested that a short duration of adjuvant chemotherapy ( $<8$ cycles) is detrimental for DFS and OS of patients surgically operated on for gastric cancer.

The significance of the timing of the commencement of adjuvant chemotherapy in many solid tumors remains controversial. In colon cancer, a German study found a positive effect of early ( $<27$ days) administration of adjuvant chemotherapy on DFS, but not on survival (46). Chau et al (47) reported a significant OS advantage for patients who started adjuvant chemotherapy within 8 weeks from surgery; this latter finding was confirmed by Hershman et al in elderly patients ( $>65$ years); however, disease-specific mortality was found to significantly worsen only after a longer than 3-month interval (48). In breast cancer, two large retrospective analyses $(49,50)$ failed to demonstrate any effect of early initiation of adjuvant chemotherapy on survival. However, starting adjuvant chemotherapy within 21 days from surgery has been suggested to be favorable for pre-menopausal patients with receptor-negative tumors (51). One of the reasons why some oncologists prefer pre-operative chemotherapy is that surgery for gastric cancer is demanding, post-operative complications are frequent and convalescence is often long-lasting, not allowing for the timely commencement of chemotherapy. Most trials have 6 (36) or 
8 weeks $(19-21,34)$ from surgery as eligibility criteria for entry, thus they do not include patients who cannot be randomized within this time interval. Our results suggested that starting adjuvant chemotherapy more than 2 months after surgery does not affect long-term outcome and does not nullify the effect of adjuvant chemotherapy following radical surgery.

Patients who receive radical resection for gastric cancer usually have low values of hemoglobin due to pre-operative bleeding, prolonged fasting and impaired iron absorption. Anemia is frequently reported as a negative predictor of response to chemoradiotherapy (52-54). In early gastric cancer, pre-operative hemoglobin of less than $12 \mathrm{~g} / \mathrm{dl}$ has been associated with poorer survival (55), and in a metastatic setting, hemoglobin of less than $10 \mathrm{~g} / \mathrm{dl}$ has been correlated with worse response rate and increased risk of death (56). In our patients, starting adjuvant chemotherapy with hemoglobin values of less than $11.0 \mathrm{~g} / \mathrm{dl}$ did not affect the number of delivered cycles of FOLFOX-4 or long-term prognosis. However, basal hemoglobin of less than $11 \mathrm{~g} / \mathrm{dl}$ was associated with increased hematological toxicity, since $53.8 \%$ of these patients experienced grade $\geq 2$ anemia during chemotherapy.

Although the combination of 5FU and oxaliplatin has been extensively studied in metastatic gastric cancer (57), there are a few reports regarding the adjuvant setting mainly in Chinese populations $(58,59)$. To our knowledge, our series is the largest in the literature to address the feasibility and tolerability of FOLFOX-4 regimen in Caucasian patients surgically operated on for gastric cancer. Grade 3-4 hematological toxicity registered in our patients is comparable to that reported in the Mosaic study (38) in patients operated on for colon cancer, neutropenia being the most frequent adverse event. Gastrointestinal tolerability was good, since less than $4 \%$ of the patients experienced grade 3 vomiting or diarrhea. Severe peripheral neuropathy occurred in 1 patient, much less than reported in the Mosaic study (12.4\%), probably because the median number of delivered cycles of chemotherapy was lower (8 vs. 12 cycles).

The prognostic role of gender in solid tumors is questionable and is often attributed to chance. However, in gastric cancer some experimental evidence suggests that estrogenpositive tumors are more frequent in women and more aggressive $(60,61)$. The reason for such behavior remains poorly understood; however, it can be explained by a crosstalk between estrogen receptors and epidermal growth factor receptor pathways in gastric cancer cells (62). In our study, we confirmed that women have a significantly worse prognosis and that the increased risk of recurrence at multivariate analysis is independent from other prognostic factors (the interactions gender-stage and gender-number of delivered cycles were not significant). Thus, it may be speculated that it is due to intrinsic growth characteristics of the tumor cells.

In conclusion, our experience suggests that FOLFOX-4 is a feasible and manageable regimen as adjuvant treatment and represents a valid option when a platinum + fluoropyrimidine scheme is indicated for radically resected gastric cancer patients. Moreover, although demonstrated in a limited number of patients, the present study suggests that at least 4 months of adjuvant chemotherapy should be administered to obtain the most beneficial effect and that a short interval between surgery and the commencement of adjuvant chemotherapy is not fundamental for the effect of adjuvant chemotherapy on prognosis.

\section{References}

1. Kamangar F, Dores GM and Anderson WF: Patterns of cancer incidence, mortality, and prevalence across five continents: defining priorities to reduce cancer disparities in different geographic regions of the world. J Clin Oncol 24: 2137-2150, 2006.

2. Jemal A, Siegel R, Ward E, Hao Y, Xu J, Murray T and Thun MJ: Cancer statistics, 2008. CA Cancer J Clin 58: 71-96, 2008.

3. Kajitani T: The general rules for the gastric cancer study in surgery and pathology. Part I. Clinical classification. Jpn J Surg 11: $127-139,1981$.

4. Dent DM, Madden MV and Price SK: Randomized comparison of R1 and R2 gastrectomy for gastric carcinoma. Br J Surg 75: 110-112, 1988.

5. Robertson CS, Chung SC, Woods SD, Griffin SM, Raimes SA, Lau JT and Li AK: A prospective randomized trial comparing R1 subtotal gastrectomy with R3 total gastrectomy for antral cancer. Ann Surg 220: 176-182, 1994.

6. Cuschieri A, Weeden S, Fielding J, et al: Patient survival after D1 and D2 resections for gastric cancer: long-term results of the MRC randomized surgical trial. Surgical Co-operative Group. Br J Cancer 79: 1522-1530, 1999.

7. Bonenkamp JJ, Hermans J, Sasako M, et al: Extended lymph-node dissection for gastric cancer. N Engl J Med 340: 908-914, 1999.

8. The Gastrointestinal Tumor Study Group: Controlled trial of adjuvant chemotherapy following curative resection for gastric cancer. Cancer 49: 1116-1122, 1982.

9. Higgins GA, Amadeo JH, Smith DE, Humphrey EW and Keehn RJ: Efficacy of prolonged intermittent therapy with combined 5-FU and methyl-CCNU following resection for gastric carcinoma. A Veterans Administration Surgical Oncology, Group report. Cancer 52: 1105-1112, 1983.

10. Engstrom PF, Lavin PT, Douglass HO Jr and Brunner $\mathrm{KW}$ : Postoperative adjuvant 5-fluorouracil plus methyl-CCNU therapy for gastric cancer patients. Eastern Cooperative Oncology Group study (EST 3275). Cancer 55: 1868-1873, 1985.

11. Allum WH, Hallissey MT and Kelly KA: Adjuvant chemotherapy in operable gastric cancer. 5 year follow-up of first British Stomach Cancer Group trial. Lancet 1: 571-574, 1989.

12. Coombes RC, Schein PS, Chilvers CE, et al: A randomized trial comparing adjuvant fluorouracil, doxorubicin, and mitomycin with no treatment in operable gastric cancer. International Collaborative Cancer Group. J Clin Oncol 8: 1362-1369, 1990.

13. Krook JE, O'Connell MJ, Wieand HS, et al: A prospective, randomized evaluation of intensive-course 5-fluorouracil plus doxorubicin as surgical adjuvant chemotherapy for resected gastric cancer. Cancer 67: 2454-2458, 1991.

14. Grau JJ, Estape J, Alcobendas F, Pera C, Daniels M and Teres J: Positive results of adjuvant mitomycin- $\mathrm{C}$ in resected gastric cancer: a randomised trial on 134 patients. Eur J Cancer 29A: 340-342, 1993.

15. Lise M, Nitti D, Marchet A, et al: Final results of a phase III clinical trial of adjuvant chemotherapy with the modified fluorouracil, doxorubicin and mitomycin regimen in resectable gastric cancer. J Clin Oncol 13: 2757-2763, 1995.

16. Macdonald JS, Fleming TR, Peterson RF, et al: Adjuvant chemotherapy with 5-FU, adriamycin, and mitomycin-C (FAM) versus surgery alone for patients with locally advanced gastric adenocarcinoma: A Southwest Oncology Group study. Ann Surg Oncol 2: 488-494, 1995.

17. Neri B, de Leonardis V, Romano S, et al: Adjuvant chemotherapy after gastric resection in node-positive cancer patients: a multicentre randomised study. Br J Cancer 73: 549-552, 1996.

18. Cirera L, Balil A, Batiste-Alentorn E, et al: Randomized clinical trial of adjuvant mitomycin plus tegafur in patients with resected stage III gastric cancer. J Clin Oncol 17: 3810-3815, 1999.

19. Bajetta E, Buzzoni R, Mariani L, et al: Adjuvant chemotherapy in gastric cancer: 5-year results of a randomised study by the Italian Trials in Medical Oncology (ITMO) Group. Ann Oncol 13: 299-307, 2002.

20. De Vita F, Giuliani F, Orditura M, et al: Adjuvant chemotherapy with epirubicin, leucovorin, 5-fluorouracil and etoposide regimen in resected gastric cancer patients: a randomized phase III trial by the Gruppo Oncologico Italia Meridionale (GOIM 9602 Study). Ann Oncol 18: 1354-1358, 2007. 
21. Di Costanzo F, Gasperoni S, Manzione L, et al: Adjuvant chemotherapy in completely resected gastric cancer: a randomized phase III trial conducted by GOIRC. J Natl Cancer Inst 100 : 388-398, 2008

22. Hermans J, Bonenkamp JJ, Boon MC, Bunt AM, Ohyama S, Sasako M and van de Velde CJ: Adjuvant therapy after curative resection for gastric cancer: meta-analysis of randomized trials. J Clin Oncol 11: 1441-1447, 1993.

23. Hermans J and Benekamp K: In replay. J Clin Oncol 12: 879-880, 1994.

24. Earle CC and Maroun JA: Adjuvant chemotherapy after curative resection for gastric cancer in non-Asian patients: revisiting a meta-analysis of randomised trials. Eur J Cancer 35: 1059-1064, 1999.

25. Mari E, Floriani I, Tinazzi A, et al: Efficacy of adjuvant chemotherapy after curative resection for gastric cancer: a metaanalysis of published randomised trials. A study of the GISCAD (Gruppo Italiano per lo Studio dei Carcinomi dell' Apparato Digerente). Ann Oncol 11: 837-843, 2000

26. Gianni L, Panzini I, Tassinari D, Mianulli AM, Desiderio F and Ravaioli A: Meta-analyses of randomized trials of adjuvant chemotherapy in gastric cancer. Ann Oncol 12: 1178-1180, 2001.

27. Panzini I, Gianni L, Fattori PP, et al: Adjuvant chemotherapy in gastric cancer: a meta-analysis of randomized trials and a comparison with previous meta-analyses. Tumori 88: 21-27, 2002

28. Hu JK, Chen ZX, Zhou ZG, et al: Intravenous chemotherapy for resected gastric cancer: meta-analysis of randomized controlled trials. World J Gastroenterol 8: 1023-1028, 2002.

29. Janunger KG, Hafstrom L and Glimelius B: Chemotherapy in gastric cancer: a review and updated meta-analysis. Eur J Surg 168: 597-608, 2002

30. Liu TS, Wang Y, Chen SY and Sun YH: An updated metaanalysis of adjuvant chemotherapy after curative resection for gastric cancer. Eur J Surg Oncol 34: 1208-1216, 2008.

31. Zhao SL and Fang JY: The role of postoperative adjuvant chemotherapy following curative resection for gastric cancer: a meta-analysis. Cancer Invest 26: 317-325, 2008.

32. Sun P, Xiang JB and Chen ZY: Meta-analysis of adjuvant chemotherapy after radical surgery for advanced gastric cancer. Br J Surg 96: 26-33, 2009.

33. Oba K: Efficacy of adjuvant chemotherapy using tegafur-based regimen for curatively resected gastric cancer: update of a metaanalysis. Int J Clin Oncol 14: 85-89, 2009.

34. Macdonald JS, Smalley SR, Benedetti J, et al: Chemoradiotherapy after surgery compared with surgery alone for adenocarcinoma of the stomach or gastroesophageal junction. N Engl J Med 345: 725-730, 2001.

35. Cunningham D, Allum WH, Stenning SP, et al: Perioperative chemotherapy versus surgery alone for resectable gastroesophageal cancer. N Engl J Med 355: 11-20, 2006.

36. Sakuramoto S, Sasako M, Yamaguchi T, et al: Adjuvant chemotherapy for gastric cancer with S-1, an oral fluoropyrimidine. N Engl J Med 357: 1810-1820, 2007.

37. Cunningham D, Starling N, Rao S, et al: Capecitabine and oxaliplatin for advanced esophagogastric cancer. N Engl J Med 358: 36-46, 2008

38. Andre T, Boni C, Navarro M, et al: Improved overall survival with oxaliplatin, fluorouracil and leucovorin as adjuvant treatment in stage II or III colon cancer in the MOSAIC trial. J Clin Oncol 27: 3109-3116, 2009.

39. Kuebler JP, Wieand HS, O'Connell MJ, et al: Oxaliplatin combined with weekly bolus fluorouracil and leucovorin as surgical adjuvant chemotherapy for stage II and III colon cancer: results from NSABP C-07. J Clin Oncol 25: 2198-2204, 2007.

40. Kaplan EL and Meier P: Nonparametric estimation for incomplete observations. J Am Stat Assoc 53: 457-481, 1958.

41. Peto R and Peto J: Asymptotically efficient rank invariant test procedures. J R Stat Soc 135A: 185-206, 1972.

42. Cox DR: Regression models and life tables (with discussion). J R Stat Soc 4B: 187-220, 1972

43. Qiu MZ, Teng KY, Ruan DY, et al: Impact of adjuvant chemotherapy duration on 3-year disease-free survival of colorecta carcinoma patients after radical resection. Chin J Cancer 28 743-748, 2009.

44. Neugut AI, Matasar M, Wang X, et al: Duration of adjuvant chemotherapy for colon cancer and survival among the elderly. J Clin Oncol 24: 2368-2375, 2006
45. Yen MS, Twu NF, Lai CR, Horng HC, Chao KC and Juang CM Importance of delivered cycles and nomogram for intraperitoneal chemotherapy in ovarian cancer. Gynecol Oncol 114: 415-419, 2009.

46. Arkenau HT, Bermann A, Rettig K, Strohmeyer G and Porschen R: 5-Fluorouracil plus leucovorin is an effective adjuvant chemotherapy in curatively resected stage III colon cancer: long-term follow-up results of the adjCCA-01 trial. Ann Oncol 14: 395-399, 2003.

47. Chau I, Norman AR, Cunningham D, et al: A randomised comparison between 6 months of bolus fluorouracil/leucovorin and 12 weeks of protracted venous infusion fluorouracil as adjuvant treatment in colorectal cancer. Ann Oncol 16: 549-557, 2005.

48. Hershman D, Hall MJ, Wang X, Jacobson JS, McBride R, Grann VR and Neugut AI: Timing of adjuvant chemotherapy initiation after surgery for stage III colon cancer. Cancer 107: 2581-2588, 2006.

49. Cold S, During M, Ewertz M, Knoop A and Moller S: Does timing of adjuvant chemotherapy influence the prognosis after early breast cancer? Results of the Danish Breast Cancer Cooperative Group (DBCG). Br J Cancer 93: 627-632, 2005.

50. Jara SC, Ruiz A, Martin M, et al: Influence of timing of initiation of adjuvant chemotherapy over survival in breast cancer: a negative outcome study by the Spanish Breast Cancer Research Group (GEICAM). Breast Cancer Res Treat 101: 215-223, 2007.

51. Colleoni M, Bonetti M, Coates AS, et al: Early start of adjuvant chemotherapy may improve treatment outcome for premenopausal breast cancer patients with tumors not expressing estrogen receptors. The International Breast Cancer Study Group. J Clin Oncol 18: 584-590, 2000

52. Box B, Lindsey I, Wheeler JM, et al: Neoadjuvant therapy for rectal cancer: improved tumor response, local recurrence, and overall survival in nonanemic patients. Dis Colon Rectum 48: 1153-1160, 2005.

53. Lee SD, Park JW, Park KS, et al: Influence of anemia on tumor response to preoperative chemoradiotherapy for locally advanced rectal cancer. Int J Colorectal Dis 24: 1451-1458, 2009.

54. Ferrandina G, Distefano M, Smaniotto D, et al: Anemia in patients with locally advanced cervical carcinoma administered preoperative radiochemotherapy: association with pathological response to treatment and clinical outcome. Gynecol Oncol 103 $500-505,2006$

55. Shen JG, Cheong JH, Hyung WJ, Kim J, Choi SH and Noh SH: Pretreatment anemia is associated with poorer survival in patients with stage I and II gastric cancer. J Surg Oncol 91: 126-130, 2005.

56. Park SH, Lee J, Lee SH, et al: Anemia is the strongest prognostic factor for outcomes of 5-fluorouracil-based first-line chemotherapy in patients with advanced gastric cancer. Cancer Chemother Pharmacol 57: 91-96, 2006.

57. De Vita F, Orditura M, Matano E, et al: A phase II study of biweekly oxaliplatin plus infusional 5-fluorouracil and folinic acid (FOLFOX-4) as first-line treatment of advanced gastric cancer patients. Br J Cancer 92: 1644-1649, 2005.

58. Fang Y, Wang YJ, Li F and Li J: Oxaliplatin in combination with calcium folinate and fluorouracil as neoadjuvant chemotherapy in the treatment of advanced gastric cancer. Zhonghua Wei Chang Wai Ke Za Zhi 9: 510-512, 2006

59. Zhao L, Li XY, Bai CM and Chen SC: Post-operative adjuvant treatment with oxaliplatin, fluorouracil, and leucovorin for local advanced gastric cancer. Zhonghua Yi Xue Za Zhi 88: 1264-1266, 2008.

60. Matsui M, Kojima O, Kawakami S, Uehara Y and Takahashi T: The prognosis of patients with gastric cancer possessing sex hormone receptors. Surg Today 22: 421-425, 1992.

61. Harrison JD, Morris DL, Ellis IO, Jones JA and Jackson I: The effect of tamoxifen and estrogen receptor status on survival in gastric carcinoma. Cancer 64: 1007-1010, 1989

62. Koullias GJ, Kouraklis GP, Raftopoulos IS, Davaris PS Papadopoulos SA and Golematis BC: Increased estrogen receptor and epidermal growth factor receptor gene product co-expression in surgically resected gastric adenocarcinomas. J Surg Oncol 63: 166-171, 1996. 